\title{
Desempenho de sementes de soja tratadas com bioestimulante sob diferentes condições de potencial osmótico
}

\author{
Lucas Tatto \\ Stela Maris Kulczynski \\ Cristiano Bellé \\ Daniel Morin \\ Felipe Minetto Rubin \\ Marcos Piovesan Uliana
}

Universidade Federal de Santa Maria (UFSM), Campus de Frederico Westphalen, Departamento de Agronomia, Frederico Westphalen, RS

E-mails: lucastattoagronomia@yahoo.com.br stelmk@terra.com.br crbelle@gmail.com danielmorin@hotmail.com.br felipeminettorubin@yahoo.com.br mp.uliana@hotmail.com

Recebido em: 28 dezembro 2017. Aceito em: 18 abril 2018.

DOI: http://dx.doi.org/10.21674/2448-0479.43.397-408

\section{Resumo}

O trabalho teve como objetivo verificar a influência do tratamento de sementes com bioestimulante sob condições de diferentes potenciais osmóticos e seu efeito sobre o potencial fisiológico da semente e o desenvolvimento inicial da cultura da soja. Os tratamentos foram arranjados em esquema fatorial $2 \times 5$, sendo, presença ou ausência do bioestimulante, e cinco potenciais osmóticos $(0,0 ;-0,3 ;-0,6 ;-0,9 ;-1,2$ $\mathrm{MPa}$ ), com quatro repetições. A qualidade fisiológica das sementes foi determinada através dos testes de germinação - primeira contagem da germinação; classificação do vigor das plântulas; comprimento e matéria seca da parte aérea e das raízes das plântulas. De acordo com os testes realizados, verificouse que o decréscimo no potencial osmótico, induzido por solução de $\mathrm{NaCl}$, reduz a germinação e o vigor de sementes de soja, e que o tratamento de sementes com bioestimulante proporciona aumento no desempenho de plântulas de soja e induz resistência a condições de estresse hídrico.

Palavras-chave: Glycine max (L.) Merrill. Indutor de resistência. Restrição hídrica. Germinação. Vigor de sementes.

\section{Abstract \\ Performance soybean seeds treated with biostimulant under different conditions the osmotic potential}

The research aimed to investigate the influence of seed treatment with bio-stimulant under conditions of different osmotic potential and its influence on the physiological potential of seed and early development of the soybean crop. The treatments were composed by the combination of the presence or absence of biostimulant at different osmotic potential $(0.0,-0.3,-0.6,-0.9,-1.2 \mathrm{MPa})$ simulated with solution $\mathrm{NaCl}$, factorial $2 \times 5$, with four replications. The physiological seed quality was determined by 
the germination test, first count of germination; classification of seedling vigor; length and dry matter of shoot and root of seedlings. According to the tests performed it was found that the decrease in osmotic potential, induced $\mathrm{NaCl}$ solution, reduces the germination and vigor soybean seeds and seed treatment with biostimulant provides an increase in the soybean seedling performance and induces resistance to water stress.

Keywords: Glycine max (L.) Merrill. Resistance inducer. Fluid restriction. Germination. Vigor seed.

\section{Introdução}

Na cultura da soja (Glycine max (L.) Merrill), a obtenção de uma lavoura com população adequada de plantas depende da correta utilização de diversas práticas, cujo sucesso está diretamente condicionado à utilização de sementes de boa qualidade. Todavia, frequentemente, a semeadura não é realizada em condições ideais e, dentre os fatores negativos, destacam-se as adversidades ocasionadas por fatores climáticos, principalmente o déficit hídrico, o inadequado manejo químico do solo e o uso de tratos culturais não recomendados.

Os períodos de maior exigência hídrica para a cultura ocorrem entre a germinação e a emergência das plântulas, assim como no florescimento, onde a falta de água proporciona diminuição no estande inicial da lavoura, além de ocasionar considerável redução da produtividade, respectivamente. Períodos de estiagem são comuns nas áreas tradicionalmente utilizadas para o cultivo de soja no Brasil, principalmente no Sul, onde são poucas as áreas cultivadas sob irrigação.

A necessidade hídrica das culturas condiciona as atividades fisiológicas e metabólicas das plantas. Quanto maior a disponibilidade de água no solo, melhor a capacidade de absorção de nutrientes pelas raízes e maior a eficiência fotossintética, resultando em um máximo rendimento agrícola (BALDO et al., 2009).

Com o intuito de alcançar maiores retornos econômicos pelo incremento na produtividade da cultura da soja, faz-se necessária a continuidade no processo de geração de informações, através de pesquisa com novas tecnologias que avalie práticas inovadoras de manejo, como o uso de bioestimulantes incorporado ao tratamento de sementes.

A ação dos bioestimulantes depende das condições ambientais, assim como das características e potencialidades genéticas das plantas (VIEIRA; MONTEIRO, 2002). Através destas substâncias, pode-se interferir em diversos processos fisiológicos e/ou morfológicos, como a germinação, o crescimento vegetativo, o florescimento, a frutificação, a senescência e a abscisão. Esta interferência pode ocorrer pela aplicação dessas substâncias via sementes, via solo ou via foliar. Para isso, elas precisam ser absorvidas a fim de que que possam exercer sua atividade (KLAHOLD et al., 2006).

Alguns trabalhos têm demonstrado o efeito de bioestimulantes como ação promotora na cultura da soja (ÁVILA et al., 2008; MOTERLE et al., 2008), apontando resultados relativos ao desempenho das plantas, componentes de produção e sobre a qualidade de sementes. A utilização de sementes com qualidade superior e o emprego de produtos que possibilitem melhoria de seu desempenho no campo são elementos importantes para que se alcancem altas produtividades. Entretanto, há poucos trabalhos que relatam os resultados de germinação e vigor das sementes, sob a aplicação de bioestimulantes, quando estas são submetidas a estresses, como a deficiência hídrica.

Diante do exposto, o objetivo deste trabalho foi avaliar a influência do tratamento de sementes com bioestimulante sob condições de diferentes potenciais osmóticos e seu efeito sobre o seu potencial fisiológico, assim como no desenvolvimento inicial da cultura da soja. 


\section{Material e Métodos}

Foram utilizadas sementes certificadas de soja, cultivar Nideria 5909 RG, as quais inicialmente foram tratadas com fipronil + tiofanato metílico + piraclostrobina, na concentração $200 \mathrm{ml} / 100 \mathrm{~kg}$ de sementes. Foi adotado o delineamento experimental inteiramente casualizado em esquema fatorial $2 x$ 5 (ausência ou presença do bioestimulante $x$ níveis de potencial osmótico), com quatro repetições.

Como bioestimulante, foi utilizado o produto FertiactylLeg, o qual apresenta a seguinte composição: Cobalto $(0,5 \% \mathrm{~m} / \mathrm{v})$, Molibdênio $(3 \% \mathrm{~m} / \mathrm{v})$, Carbono orgânico $(0,5 \% \mathrm{~m} / \mathrm{v})$ e ácido giberélico $(0,005 \% \mathrm{~m} / \mathrm{v})$, mais o tratamento sem bioestimulante em diferentes condições de estresse hídrico simuladas com a solução de cloreto de sódio $(\mathrm{NaCl})$, sob diferentes níveis de potencial osmótico.

O bioestimulante foi adicionado ao tratamento de sementes sendo utilizada a dose de $200 \mathrm{ml} / 100$ $\mathrm{kg}$ sementes. Todos os testes foram realizados em substrato de papel germitest, o qual foi embebido em soluções contendo $\mathrm{NaCl}$ nos níveis: 0,$0 ;-0,3 ;-0,6 ;-0,9 ;-1,2 \mathrm{MPa}$. O nível zero foi usado como testemunha (controle), utilizando-se apenas água destilada. As quantidades de $\mathrm{NaCl}$ para se obterem os referidos potenciais foram calculadas com base na equação proposta por Salisbury e Ross (1991).

Para a avaliação da qualidade fisiológica das sementes, realizaram-se as seguintes determinações: germinação; primeira contagem da germinação; classificação do vigor das plântulas; desempenho de plântulas e matéria seca da parte área e da raiz.

O teste de germinação foi realizado entre papel germitest, sendo duas folhas para base e uma para cobertura, umedecidas com as diferentes soluções de $\mathrm{NaCl}$, na proporção de 2,5 vezes a massa seca do papel. Em seguida, as folhas foram dispostas a fim de se formar "rolos", sendo posteriormente estes envolvidos em sacos de polietileno e colocados em germinador regulado à temperatura constante de $25^{\circ} \mathrm{C}$. Foram utilizadas quatro repetições com 100 sementes para cada, sendo as avaliações realizadas aos oito dias após a semeadura. Os resultados foram expressos em porcentagem de plântulas normais, anormais e as sementes mortas (BRASIL, 2009).

A primeira contagem da germinação foi conduzida conjuntamente com o teste de germinação, sendo a avaliação realizada após cinco dias do início do teste, e os resultados expressos em porcentagem de plântulas normais germinadas (NAKAGAWA, 1999).

A classificação do vigor foi realizada simultaneamente à última contagem do teste de germinação, onde as plântulas normais foram classificadas como "fortes" e "fracas". Foram consideradas plântulas normais "fortes" as que não apresentavam pequenas irregularidades em quaisquer de suas estruturas essenciais, como sistema radicular, hipocótilo, cotilédone e aspecto geral da plântula. As normais "fracas" também se apresentavam sadias, sem defeitos, porém, com menor desenvolvimento (NAKAGAWA, 1999).

O comprimento de plântulas foi avaliado pelo teste composto por quatro amostras por repetições de dez sementes envolvidas entre papel, sendo duas folhas para base e uma para cobertura, umedecidas com as diferentes soluções de $\mathrm{NaCl}$, na proporção de 2,5 vezes a massa seca do papel, formando linha única a dez centímetros da borda superior da folha. Em seguida, as folhas foram dispostas a fim de se formarem "rolos", sendo estes envolvidos em sacos de polietileno e colocados em germinador regulado à temperatura constante de 25C (NAKAGAWA,1999). A avaliação foi realizada no oitavo dia, seccionando-se a parte aérea (sem os cotilédones) e a raiz das plântulas normais, medindo-se os comprimentos com auxílio de régua, sendo os resultados expressos em centímetros.

Para determinação da matéria seca de parte aérea e da raiz, as plântulas foram colocadas em sacos de papel e levadas para secagem em estufa a $80^{\circ} \mathrm{C}$ por 48 horas. Ao término da secagem, 
realizou-se a determinação da massa das plântulas em balança analítica de precisão de $0,001 \mathrm{~g}$ (NAKAGAWA,1999).

Os dados foram analisados com o programa SISVAR (FERREIRA, 2011), usando o teste F para análise de variância, o teste Tukey a $5 \%$ de probabilidade para a comparação de médias entre a aplicação e ausência do bioestimulante, e regressão (linear ou quadrática) para os níveis de potencial osmótico.

\section{Resultados e Discussão}

A análise dos resultados expressos na Tabela 1 permite verificar que o uso de bioestimulante e estresse hídrico simulado por diferentes potenciais osmóticos interferem nos atributos fisiológicos das sementes de soja. Constatou-se que o bioestimulante (FertiactylLeg) usado no tratamento das sementes proporcionou maior quantidade de germinação, menor número de plântulas anormais e sementes mortas em relação às não tratadas (testemunha) (Tabela 1). Resultados semelhantes foram encontrados com o uso do bioestimulante Stimulate $(0,005 \%$ do ácido indolbutirico - IBA, 0,009\% de citocinina e $0,005 \%$ de ácido giberélico) na germinação de sementes de algodão (BELMONT et al., 2004; SANTOS; VIEIRA, 2005) e feijoeiro (VIEIRA; CASTRO, 2001).

Analisando-se 0 efeito do estresse hídrico, constata-se que não houve diferença entre os potencias maiores $(-0,3$ e - $0,6 \mathrm{MPa})$ em relação a testemunha. Porém, os potenciais menores $(-0,9$ e$1,2 \mathrm{MPa}$ ) influenciaram negativamente o número de sementes germinadas na primeira contagem e na germinação, no número de plântulas anormais e de sementes mortas (Tabela 1). $O$ decréscimo no percentual de germinação em condições de estresses hídricos induzidos por potencias osmóticos negativos também foram visualizados em sementes de soja, feijão, arroz, algodoeiro e canola (MACHADO NETO et al., 2006; LIMA et al., 2005; LIMA et al., 2007; ÁVILA et al., 2007).

Analisando-se 0 efeito do estresse hídrico, constata-se que não houve diferença entre os potencias maiores $(-0,3$ e - $0,6 \mathrm{MPa})$ em relação a testemunha. Porém, os potenciais menores $(-0,9$ e$1,2 \mathrm{MPa}$ ) influenciaram negativamente o número de sementes germinadas na primeira contagem e na germinação, no número de plântulas anormais e de sementes mortas (Tabela 1). O decréscimo no percentual de germinação em condições de estresses hídricos induzidos por potencias osmóticos negativos também foram visualizados em sementes de soja, feijão, arroz, algodoeiro e canola (MACHADO NETO et al., 2006; LIMA et al., 2005; LIMA et al., 2007; ÁVILA et al., 2007).

Avaliando-se o vigor das sementes através da classificação normais fortes e fracas, matéria seca e comprimento de plântulas, verifica-se que o uso do bioestimulante aplicado via sementes proporcionou maior número de plântulas com maior vigor determinado pelo maior comprimento e massa seca da parte aérea e da raiz das plântulas (Tabela 1). 
Tabela 1 - Valores médios da primeira contagem (PC), germinação $(G)$, sementes mortas (SM), plântulas anormais (AN), plântulas normais fortes (FO) e fracas (FR), comprimento da parte aérea (CPA) e raiz (CRA) e matéria seca da parte aérea (MSA) e da raiz (MSR), de sementes de soja (Glycine max) cultivar Nidera 5909, tratadas com bioestimulante e submetidas a diferentes potenciais osmóticos.

\begin{tabular}{|c|c|c|c|c|c|c|c|c|c|c|}
\hline Bioestimulante (B) & PC (\%) & G & SM & AN (\%) & FO (\%) & FR (\%) & $\mathrm{CP}(\mathrm{mm})$ & $\mathrm{CR}(\mathrm{mm})$ & MSA (g) & $\operatorname{MSR}(g)$ \\
\hline Com & 93 a & 92 a & $3 b$ & $6 \mathrm{~b}$ & $60,20 \mathrm{a}$ & $30,40 \mathrm{~b}$ & 56,15 a & 67,67 a & $0,10 \mathrm{a}$ & $0,05 \mathrm{a}$ \\
\hline Sem & $87 \mathrm{~b}$ & $86 \mathrm{~b}$ & 7 a & $9 \mathrm{a}$ & $45,40 \mathrm{~b}$ & $43,20 \mathrm{a}$ & $39,89 \mathrm{~b}$ & $47,59 \mathrm{~b}$ & $0,08 \mathrm{~b}$ & $0,04 \mathrm{~b}$ \\
\hline \multicolumn{11}{|l|}{ Conc. Salina (MPa) (CS) } \\
\hline 0 & 99,6 & 97,4 & 0 & 4,6 & 56,6 & 34,2 & 123,29 & 129,92 & 0,21 & 0,09 \\
\hline$-0,3$ & 98,8 & 95,5 & 0,6 & 6 & 62,6 & 31,7 & 69,87 & 106,22 & 0,14 & 0,08 \\
\hline$-0,6$ & 97 & 94,6 & 0,8 & 7 & 65,5 & 37,3 & 25,52 & 46,85 & 0,07 & 0,03 \\
\hline$-0,9$ & 84,1 & 83,6 & 8,3 & 8 & 55,1 & 28,5 & 14,08 & 12,51 & 0,03 & 0,01 \\
\hline$-1,2$ & 74,6 & 80 & 11,6 & 8,6 & 36,1 & 43,8 & 8,28 & 6,97 & 0,02 & 0,01 \\
\hline \multicolumn{11}{|l|}{ VALORES F } \\
\hline$B$ & $11,20^{\star \star}$ & $29,68^{\star \star}$ & $16,12^{* *}$ & $13,44^{\text {** }}$ & $46,60^{* \star}$ & $33,87^{\star \star}$ & $34,03^{\star \star}$ & $62,60^{\star \star *}$ & $17,48^{\star \star}$ & $6,18^{\star *}$ \\
\hline CS & $80,88^{\star \star}$ & $72,09^{\star \star}$ & $50,50^{\star \star}$ & $4,40^{\star \star}$ & $50,73^{\star \star}$ & $14,07^{\text {** }}$ & $723,36^{\star \star}$ & $919,10^{\star \star}$ & $507,20^{\star \star}$ & $127,80^{\star \star *}$ \\
\hline $\mathrm{B} \times \mathrm{CS}$ & $2,32^{\star}$ & $5,56^{\star \star}$ & $4,71^{\text {** }}$ & $2,56^{\star}$ & $1,74^{\star}$ & $3,52^{\star \star}$ & $10,71^{\star \star}$ & 15,44 ** & $4,96^{\star \star}$ & $0,71^{\mathrm{ns}}$ \\
\hline CV (\%) & 4,67 & 3,55 & 10,59 & 18,28 & 10,1 & 15,42 & 12,94 & 10,46 & 13,77 & 25,14 \\
\hline
\end{tabular}

Médias seguidas pela mesma letra, na coluna, não diferem entre si pelo teste de Tukey, ao nível de $5 \%$ de probabilidade. ${ }^{\text {ns }}$, ${ }^{*}$ **: são não significativo e significativo a $5 \%$ e $1 \%$, de probabilidade.

O efeito positivo do uso do bioestimulante sobre o desenvolvimento de plântulas também foi observado por outros autores, ao aplicarem Stimulate em sementes de algodoeiro (SANTOS; VIEIRA, 2005) e feijoeiro (SILVA et al., 2009). Entretanto, outros trabalhos obtiveram resultados diferenciados, onde o uso do Stimulate (MOTERLE et al., 2011) e interações hormonais (ALBRECHT et al., 2011) não interferiram no vigor.

À medida que o potencial osmótico foi reduzido de $-0,3$ até $-1,2 \mathrm{MPa}$, a restrição hídrica aumentou, ocasionando menor comprimento de plântulas e menor acúmulo de biomassa seca (Tabela 1). Esse decréscimo acentuado no desempenho de plântulas de soja, à medida que os níveis de potencial osmótico tornaram-se mais negativos, está de acordo com os resultados obtidos por Bertagnolli et al. (2004) e Lima et al. (2007). Moraes et al. (2005), também observaram que a redução do potencial osmótico, induzido por PEG 600 e NaCl, reduziram o vigor das sementes de feijão.

Analisando a interação bioestimulante $\mathrm{x}$ potencias osmóticos (Tabela 2), verifica-se efeito positivo do uso de bioestimulantes em relação à testemunha somente em potencias mais negativos (0,9 e -1,2 MPa). Observa-se que as sementes não submetidas ao tratamento com os bioestimulantes apresentam menor percentual de germinação, maior número de plântulas anormais e sementes mortas (Tabela 2), demonstrando que os bioestimulantes induzem resistência em condições de deficiência hídrica. Entretanto, Vieira e Castro (2001), avaliando a influência do uso de ácido salicílico em sementes de feijão submetidas ao estresse hídrico, verificaram que não houve interação significativa entre os fatores irrigação e doses de ácido salicílico quanto aos parâmetros fisiológicos e componentes da produção.

A salinidade é um dos fatores abióticos que afetam a germinação das sementes, devido ao fato de provocar redução do potencial hídrico do solo, o qual, somado aos efeitos tóxicos dos sais, interfere inicialmente no processo de absorção de água pelas sementes (CAVALCANTE; PEREZ,1995). Além 
disso, a concentração total de sais presentes no solo acarreta redução na porcentagem e velocidade de germinação, devido aos efeitos tóxico e osmótico sobre o embrião (BALDO et al., 2009).

Houve interação significativa entre bioestimulante e potenciais osmóticos quanto ao vigor das sementes de soja, expresso pela primeira contagem da germinação (Tabela 2). Verifica-se o efeito positivo do uso dos bioestimulante apenas no potencial -0,9 MPa, expresso pela primeira contagem, comparativamente à testemunha. Sementes não tratadas tiveram inibição da germinação, expresso pela primeira contagem, a partir do maior potencial osmótico (Figura $1 \mathrm{D}$ ), confirmando que os potenciais hídricos mais negativos interferem nos atributos fisiológicos das sementes e que os bioestimulantes somente induzem resistência no caso de baixa deficiência hídrica.

Trabalhos onde foram avaliados apenas os efeitos negativos da deficiência hídrica sobre as sementes de soja (BERTAGNOLLI et al., 2004), algodão (LIMA et al., 2007), arroz (LIMA et al., 2005) e canola (ÁVILA et al., 2007) verificaram também que a primeira contagem de germinação foi reduzida apenas em função da influência do potencial hídrico. Essa redução no vigor pode ser atribuída ao decréscimo do potencial hídrico causado pelo aumento na concentração salina, onde o sal produz retardo no processo germinativo, impossibilitando a primeira contagem, aos cinco dias, ou seja, no período normal para a cultura.

Os resultados da Tabela 2 demonstram que tanto em condições ideais (0,0 MPa), quanto em condições de déficit hídrico (potenciais osmóticos negativos), as sementes tratadas com bioestimulante apresentaram maior percentagem de plântulas normais fortes em relação à testemunha, exceto nos potenciais - 0,9 e -1,2 MPa, onde não houve diferença significativa entre sementes tratadas ou não.

De acordo com a Figura $1 \mathrm{E}$, observa-se redução do vigor a partir do potencial -0,6 MPa, para sementes tratadas com bioestimulante e as não tratadas, respectivamente. Este resultado indica que o uso do bioestimulante atenua os efeitos adversos do estresse hídrico. Silva et al. (2009), avaliando apenas o efeito de dois bioestimulantes (Stimulate e ForthSeed) em sementes de feijão, constataram efeito positivo quanto ao vigor proporcionado por ambos os tratamentos, os quais se mostraram significativamente superiores à testemunha. A aplicação de Stimulate via sementes, segundo Santos e Vieira (2005), foi capaz de originar plântulas de algodoeiro mais vigorosas.

Entretanto, outros trabalhos avaliando a interferência do bioestimulante sobre o vigor das sementes, sem estresse hídrico, apresentaram respostas contraditórias. Moterle et al. (2011), trabalhando com sementes tratadas com bioestimulante Stimulate $\AA$ nas culturas do sorgo e trigo, não obtiveram resultados significativos quanto ao vigor. Leite et al. (2003) observaram o efeito fitotóxico da aplicação de biorreguladores (giberelina e citocinina) em sementes, através da redução do comprimento das raízes de plântulas de soja.

A percentagem de plântulas normais fracas foi menor do que plântulas normais fortes, indicando a boa qualidade das sementes utilizadas. Na Tabela 2, verifica-se que, nos potenciais osmóticos 0,0 MPa (sem estresse hídrico) e -1,2 MPa (com estresse hídrico), não se observou diferença significativa do tratamento das sementes com o bioestimulante. No entanto, nos potenciais osmóticos -0,3; - 0,6 e $0,9 \mathrm{MPa}$, as sementes sem tratamento originaram maior percentual de plântulas normais fracas (Figura $1 \mathrm{D})$. Nota-se também que o potencial osmótico de -1,2 MPa foi considerado crítico para a classificação de vigor das sementes, proporcionando maior número de plântulas normais fracas, tanto em sementes tratadas como sem tratamento. 
Tabela 2 - Valores médios de germinação, plântulas anormais, sementes mortas, primeira contagem, classificação do vigor (plântulas normais fortes e fracas), comprimento da parte aérea e da raiz, matéria seca da parte aérea e da raiz de plântulas de soja (Glycine max) cultivar Nidera 5909, com e sem aplicação de bioestimulante via sementes e submetidas a diferentes potenciais osmóticos.

\begin{tabular}{|c|c|c|c|c|c|}
\hline CONCENTRAÇÃO (MPa) & 0 & $-0,3$ & $-0,6$ & $-0,9$ & $-1,2$ \\
\hline BIOESTIMULANTE & \multicolumn{5}{|c|}{ GERMINAÇÃO (\%) } \\
\hline Com & $97,75 \mathrm{~A}$ & $95,00 \mathrm{~A}$ & $95,50 \mathrm{~A}$ & $87,00 \mathrm{~A}$ & $84,00 \mathrm{~A}$ \\
\hline \multirow[t]{2}{*}{ Sem } & $96,50 \mathrm{~A}$ & $95,00 \mathrm{~A}$ & $90,50 \mathrm{~A}$ & $73,00 \mathrm{~B}$ & $74,00 \mathrm{~B}$ \\
\hline & \multicolumn{5}{|c|}{ PLÂNTULAS ANORMAIS (\%) } \\
\hline Com & $4,50 \mathrm{~A}$ & $4,00 \mathrm{~B}$ & $7,50 \mathrm{~A}$ & $7,00 \mathrm{AB}$ & $7,50 \mathrm{~A}$ \\
\hline \multirow[t]{2}{*}{ Sem } & $6,00 \mathrm{~A}$ & $6,50 \mathrm{~A}$ & $6,50 \mathrm{~A}$ & $11,00 \mathrm{~A}$ & $11,00 \mathrm{~A}$ \\
\hline & \multicolumn{5}{|c|}{ SEMENTES MORTAS (\%) } \\
\hline Com & $0,00 \mathrm{~A}$ & $0,00 \mathrm{~A}$ & $0,50 \mathrm{~A}$ & $6,00 \mathrm{~B}$ & $8,50 \mathrm{~B}$ \\
\hline \multirow[t]{2}{*}{ Sem } & $0,00 \mathrm{~A}$ & $2,00 \mathrm{~A}$ & $2,00 \mathrm{~A}$ & $16,00 \mathrm{~A}$ & $15,00 \mathrm{~A}$ \\
\hline & \multicolumn{5}{|c|}{ PRIMEIRA CONTAGEM (\%) } \\
\hline Com & $100,00 \mathrm{~A}$ & $99,50 \mathrm{~A}$ & $98,00 \mathrm{~A}$ & $88,50 \mathrm{~A}$ & $77,00 \mathrm{~A}$ \\
\hline \multirow[t]{2}{*}{ Sem } & $99,00 \mathrm{~A}$ & $98,00 \mathrm{~A}$ & $94,50 \mathrm{~A}$ & $74,50 \mathrm{~B}$ & $70,00 \mathrm{~A}$ \\
\hline & \multicolumn{5}{|c|}{ NORMAIS FORTES (\%) } \\
\hline Com & $63,00 \mathrm{~A}$ & $66,50 \mathrm{~A}$ & $69,00 \mathrm{~A}$ & $63,00 \mathrm{~A}$ & $39,50 \mathrm{~A}$ \\
\hline \multirow[t]{2}{*}{ Sem } & $46,00 \mathrm{~B}$ & $54,50 \mathrm{~B}$ & $60,50 \mathrm{~A}$ & $39,00 \mathrm{~B}$ & $27,00 \mathrm{~B}$ \\
\hline & \multicolumn{5}{|c|}{ NORMAIS FRACAS (\%) } \\
\hline Com & $31,50 \mathrm{~A}$ & $25,50 \mathrm{~B}$ & $26,50 \mathrm{~B}$ & $24,00 \mathrm{~B}$ & $44,50 \mathrm{~A}$ \\
\hline \multirow[t]{2}{*}{ Sem } & $40,00 \mathrm{~A}$ & $40,50 \mathrm{~A}$ & $29,50 \mathrm{~A}$ & $34,00 \mathrm{~A}$ & $47,00 \mathrm{~A}$ \\
\hline & \multicolumn{5}{|c|}{ COMPRIMENTO PARTE AÉREA (mm) } \\
\hline Com & $149,4 \mathrm{~A}$ & $81,22 \mathrm{~A}$ & $25,81 \mathrm{~A}$ & $15,80 \mathrm{~A}$ & $8,50 \mathrm{~A}$ \\
\hline \multirow[t]{2}{*}{ Sem } & $103,76 \mathrm{~B}$ & $56,53 \mathrm{~B}$ & $19,47 \mathrm{~B}$ & $11,89 \mathrm{~A}$ & $7,78 \mathrm{~A}$ \\
\hline & \multicolumn{5}{|c|}{ COMPRIMENTO RAIZ (mm) } \\
\hline Com & $140,29 \mathrm{~A}$ & $130,08 \mathrm{~A}$ & $46,06 \mathrm{~A}$ & $14,37 \mathrm{~A}$ & $7,54 \mathrm{~A}$ \\
\hline \multirow[t]{2}{*}{ Sem } & $117,11 \mathrm{~B}$ & $71,87 \mathrm{~B}$ & $34,41 \mathrm{~B}$ & $8,76 \mathrm{~A}$ & $5,91 \mathrm{~A}$ \\
\hline & \multicolumn{5}{|c|}{ MATÉRIA SECA PARTE AÉREA (g) } \\
\hline Com & $0,22 \mathrm{~A}$ & $0,16 \mathrm{~A}$ & $0,06 \mathrm{~A}$ & $0,03 \mathrm{~A}$ & $0,01 \mathrm{~A}$ \\
\hline \multirow[t]{2}{*}{ Sem } & $0,19 \mathrm{~B}$ & $0,10 \mathrm{~B}$ & $0,06 \mathrm{~A}$ & $0,03 \mathrm{~A}$ & $0,01 \mathrm{~A}$ \\
\hline & \multicolumn{5}{|c|}{ MATÉRIA SECA RAIZ (g) } \\
\hline Com & $0,10 \mathrm{~A}$ & $0,09 \mathrm{~A}$ & $0,04 \mathrm{~A}$ & $0,01 \mathrm{~A}$ & $0,01 \mathrm{~A}$ \\
\hline Sem & $0,08 \mathrm{~A}$ & $0,07 \mathrm{~B}$ & $0,03 \mathrm{~A}$ & $0,01 \mathrm{~A}$ & $0,01 \mathrm{~A}$ \\
\hline
\end{tabular}




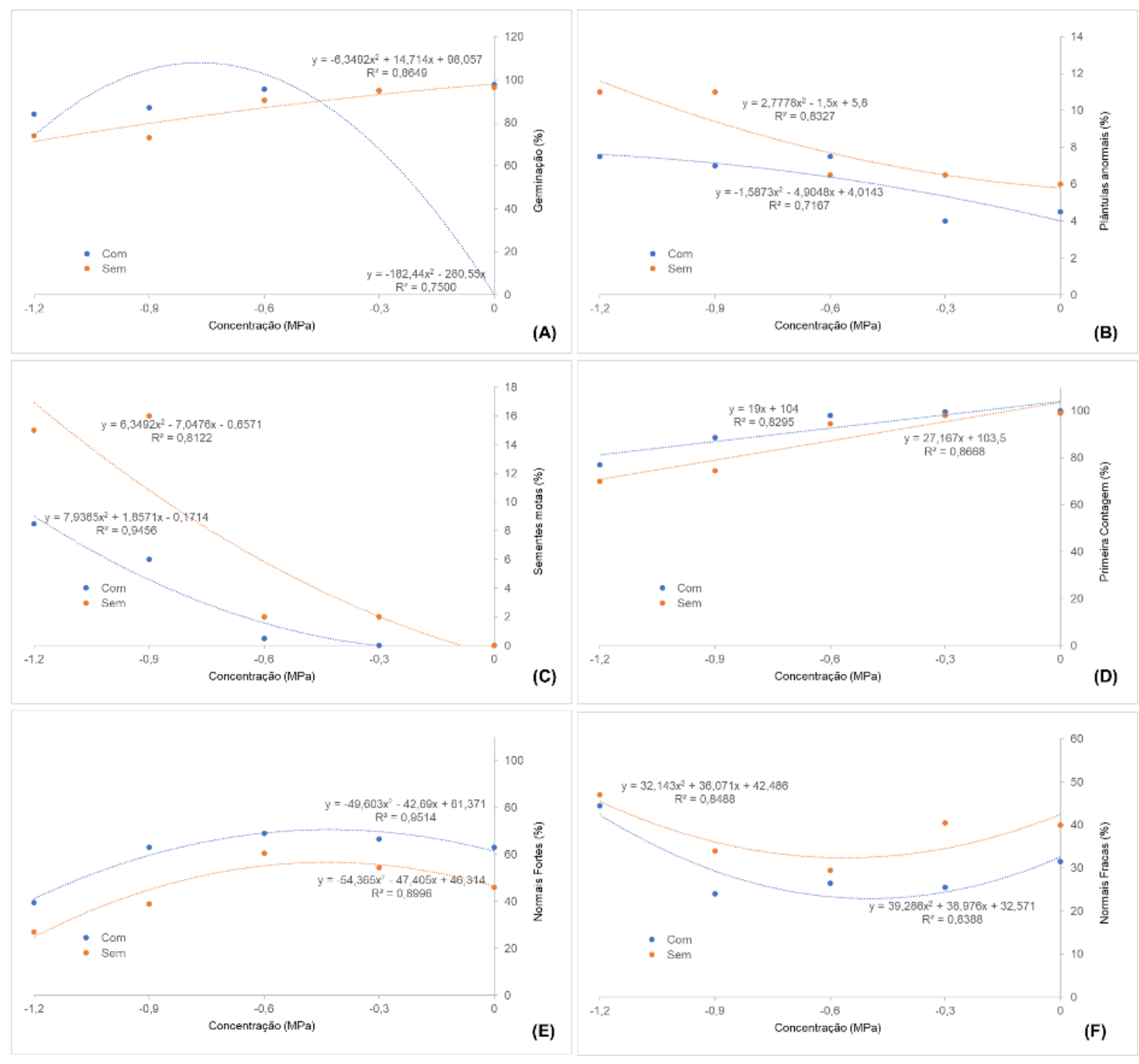

Figura 1 - Germinação (A), plântulas anormais (B), sementes mortas (C), primeira contagem (D), do vigor (plântulas normais fortes $(E)$ e plântulas normais fracas $(F)$ de soja (Glycine max) cultivar Nidera 5909, com e sem aplicação de bioestimulante via sementes e submetidas a diferentes potenciais osmóticos.

Em sementes, o vigor é mais afetado do que a germinação, quando essas são submetidas à deficiência hídrica por soluções osmóticas (MACHADO NETO et al., 2004; MORAES et al., 2005) as quais podem, também, apresentar toxidez aos sais envolvidos (MACHADO NETO et al., 2006).

O desempenho de plântulas, representado pelo comprimento da parte aérea e da raiz (Tabela 2), indica que o uso do bioestimulante, via sementes, proporcionou indução de resistência ao estresse hídrico, demonstrado por plântulas maiores, quando comparado com a testemunha (sem bioestimulante). $\mathrm{O}$ uso de reguladores vegetais como indutores de resistência ao estresse hídrico é escasso e há controvérsias quanto aos resultados (ALBRECHT et al., 2012). Resultados contraditórios foram obtidos por Baldo et al. (2009) ao avaliarem o efeito do bioestimulante Stimulate, aplicado ou não em diferentes fases do desenvolvimento do algodoeiro cv. Delta Opal, cultivado em casa de vegetação e submetido, ou não, ao estresse hídrico. Foi verificado que o bioestimulante na dose e na forma aplicada não proporcionou melhoras no crescimento das plantas quando submetidas à falta de água. 
Entretanto, em condições normais de água, os resultados obtidos são coerentes com os resultados obtidos (LEITE et al., 2003), os quais demonstraram o efeito positivo dos biorreguladores sobre o vigor, expresso através do crescimento de plântulas. Vieira \& Castro (2001) observaram que a concentração de $1,3 \mathrm{ml}$ de Stimulate para $0,5 \mathrm{~kg}$ de sementes de soja provocou crescimento radicular vertical máximo de $26,4 \mathrm{~cm}$, o que significou incremento de $9,9 \%$, em comparação ao controle que obteve $24,0 \mathrm{~cm}$ de comprimento. Para a massa seca de plântulas, o aumento foi de $55,3 \%$ na concentração de $4,1 \mathrm{ml}$ de produto, o que proporcionou um acúmulo de massa seca máxima de $0,034 \mathrm{~g}$.

Em um trabalho realizado com sementes de algodão em condição de estresse, foi verificado que o uso de Stimulate via sementes proporcionou aumento radicular total de plântulas (SANTOS; VIEIRA, 2005). Entretanto, outros trabalhos não obtiveram resultados significativos com 0 uso de bioestimulantes aplicados via sementes, sem condições de estresse, como o Stimulate em sementes de soja (MOTERLE et al., 2011) e interações hormonais (citocinina, giberelina e auxinas) em trigo (RAJALA; PELTONEN-SAINIO, 2001), os quais não proporcionaram efeito positivo sobre o comprimento da parte aérea e da raiz. Leite et al. (2003) verificaram que sementes de soja tratadas com os biorreguladores giberelina e citocinina apresentaram redução na emergência das plântulas e no comprimento das raízes, porém, com o decorrer do experimento a diferença no crescimento radicular desapareceu.

Analisando-se o desempenho de plântulas originadas de sementes tratadas e não tratadas com bioestimulante e submetidas a condições de estresse hídrico, verificou-se redução significativa no comprimento da parte aérea e da raiz, à medida que os potencias osmóticos eram mais negativos, e as plântulas com maior desenvolvimento ocorreram no potencial 0,0 MPa, sem estresse hídrico (Figura $2 \mathrm{~A}$ e B), indicando que o uso de bioestimulante foi insuficiente para induzir resistência à deficiência hídrica. Resultados coincidentes foram obtidos em sementes de soja (BERTAGNOLLI et al., 2004), algodão (LIMA et al., 2007) e arroz (LIMA et al., 2005), onde, ao avaliarem a qualidade fisiológica de sementes submetidas apenas ao teste de estresse hídrico, sem adição de bioestimulantes, verificouse redução na taxa de crescimento relativo e redução no comprimento das plântulas à medida que o potencial osmótico diminuiu.

Potenciais hídricos muito negativos, principalmente no início da embebição, promovem redução significativa na absorção de água pelas sementes, podendo inviabilizar a sequência de eventos no processo germinativo (TAIZ; ZEIGER, 2009). A baixa disponibilidade de água causa redução no crescimento, pela diminuição da expansão e do alongamento celular, devido ao decréscimo da turgescência.

Para a matéria seca da parte aérea e da raiz (Tabela 2), constatou-se efeito positivo do uso de bioestimulantes nos potenciais $0,0 \mathrm{MPa}$ (sem estresse hídrico) e - $0,3 \mathrm{MPa}$, para matéria seca da parte aérea e no potencial $-0,3 \mathrm{MPa}$, para a matéria seca da raiz, não havendo diferença nos demais potenciais osmóticos $(-0,6 ;-0,9$ e -1,2 MPa), demonstrando a pouca eficiência do uso do bioestimulante para a promoção de atenuação dos efeitos adversos do estresse hídrico no vigor das plantas de soja. 


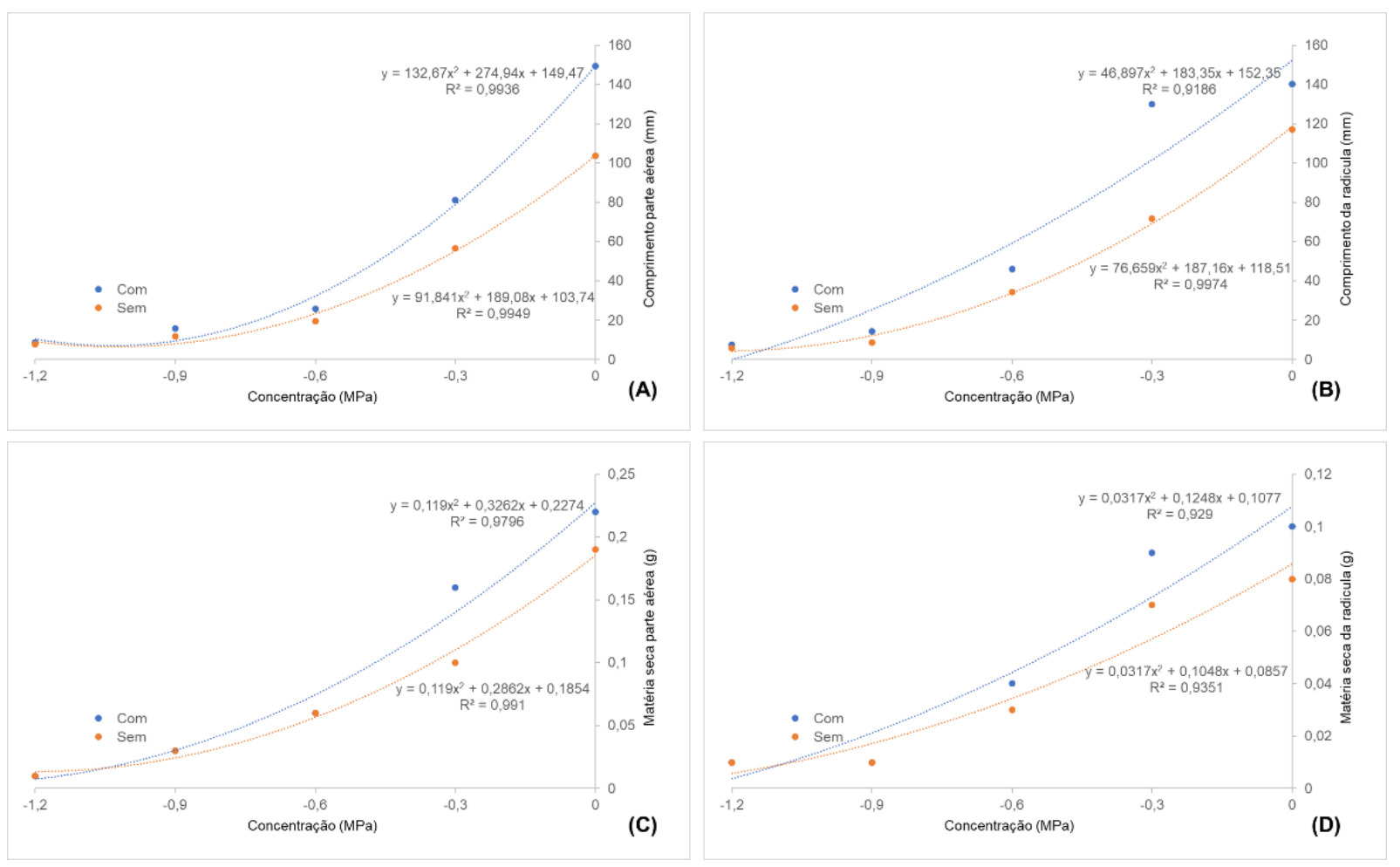

Figura 2 - Comprimento da parte aérea $(A)$ e raiz $(B)$ e matéria seca da parte aérea $(C)$ e da raiz (D) de plântulas de soja (Glycine max) cultivar Nidera 5909, com e sem aplicação de bioestimulante via sementes e submetidas a diferentes potenciais osmóticos.

À medida que os potenciais osmóticos eram mais negativos, ocorreu decréscimo no percentual de vigor, expresso pela redução da matéria seca da parte aérea e da raiz, independente do tratamento de sementes com bioestimulante (Figura $2 \mathrm{C}$; Figura $2 \mathrm{D}$ ). Resultados semelhantes foram obtidos em sementes de arroz (LIMA et al., 2005) e milho-pipoca (MOTERLE; SCAPIM, 2008) que, ao avaliarem a qualidade fisiológica de sementes submetidas apenas ao teste de estresse hídrico, sem adição de bioestimulantes, verificaram redução na matéria seca da parte aérea e da raiz, à medida que o potencial osmótico diminuiu. A redução da massa seca de plântulas em função da restrição hídrica se dá devido à demora dos processos fisiológicos e bioquímicos ou pela dificuldade de hidrólise e a mobilização das reservas armazenadas nas sementes (ÁVILA et al., 2008).

\section{Conclusão}

O decréscimo no potencial osmótico, induzido por $\mathrm{NaCl}$, reduz a germinação e o vigor das sementes de soja. O bioestimulante, aplicado via tratamento de sementes, proporciona aumento no desempenho de plântulas de soja e induz resistência a condições de estresse hídrico. 


\section{Referências}

ALBRECHT, L. P. et al. Biorregulador na composição química e na produtividade de grãos de soja. Revista Ciência Agronômica, v. 43, p. 774-782, 2012.

ALBRECHT. L. P. et al. Manejo de biorregulador nos componentes de produção e desempenho das plantas de soja. Bioscience Journal, v. 27, p. 865-876, 2011.

ÁVILA, M. R. et al. Bioregulator application, agronomic efficiency, and quality of soybean seeds. ScientiaAgricola, v. 65, p. 604-612, 2008.

ÁVILA, M. R. et al. Influência do estresse hídrico simulado com manitol na germinação de sementes e crescimento de plântulas de canola. Revista Brasileira de Sementes, v. 29, p. 98-106, 2007.

BALDO, R. et al. Comportamento do algodoeiro cultivar Delta Opal sob estresse hídrico com e sem aplicação de bioestimulante. Ciência e Agrotecnologia, v.33, p. 1804-1812, 2009.

BERTAGNOLLI, C.et al. Qualidade fisiológica e composição química de sementes de soja submetidas ao estresse salino. Revista Brasileira Agrociência, v.10, p. 287-291, 2004.

BRASIL. Ministério da Agricultura. Regras para análise de sementes. Brasília: Ministério da Agricultura, 2009.

CAVAlCANTE, A. M. B.; PEREZ, S. C. J. G. A. Efeitos dos estresses hídrico e salino sobre a germinação de sementes de Leucaenaleucocephala(Lam.) de Witt. Pesquisa Agropecuária Brasileira, v.30, p. 281-289, 1995.

FERREIRA, D. F. Sisvar: a computer statistic alanalysis system. Ciência e Agrotecnologia, v. 35, p. 1039-1042, 2011.

KLAHOLD, C. A. et al. Resposta da soja (Glycinemax (L.) Merrill) à ação de bioestimulante. Acta ScientiarumAgronomy, v. 28, p.179-185, 2006.

KRZYZANOWSKI, F. C. et al. Vigor de sementes: conceitos e testes. Londrina: ABRATES, 1999.

LEITE, V. M. et al. Gibberellin and cytokinin effects on soybean growth. ScientiaAgricola, v. 60, p. 537$541,2003$.

LIMA, L. H. G. M. et al. Atributos fisiológicos de sementes de algodoeiro submetidas a estresse salino. Revista Brasileira de Oleginosas e Fibrosas, v. 11, p. 173-184, 2007.

LIMA, M. G. S. et al. Qualidade fisiológica de sementes de arroz submetidas a estresse salino. Revista Brasileira de Sementes, v. 27, p. 54-61, 2005.

MACHADO NETO, N. B. et al. Deficiência hídrica induzida por diferentes agentes osmóticos na germinação e vigor de sementes de feijão. Revista Brasileira de Sementes, v. 28, p.142-148, 2006.

MACHADO NETO, N. B. et al. Water stress induced by mannitol and sodium chloride in soybean cultivars. Brazilian Archives of Biology and Technology, v.47, p. 521-529, 2004.

MORAES, G. A. F. et al. Comportamento de sementes de feijão sob diferentes potenciais osmóticos. Ciência Rural, v.35, p. 776-780, 2005.

MOTERLE, L. M. et al. Efeito da aplicação de biorregulador no desempenho agronômico e produtividade da soja. Acta Scientiarum. Agronomy, v. 30, p. 701-709, 2008.

MOTERLE, L. M. Efeito de biorregulador na germinação e no vigor de sementes de soja. RevistaCeres, v. 58, p. $651-660,2011$. 
MOTERLE, L. M.; SCAPIM, C.A. Influência do estresse hídrico sobre o desempenho fisiológico de sementes de híbridos simples de milho-pipoca. Ciência e Agrotecnologia, v. 32, p. 1810-1817, 2008.

NAKAGAWA, J. Testes de vigor baseados nos desempenhos das plântulas. In: KRZYZANOWSKI, F. C.; VIEIRA, R. D.; FRANÇA NETO, J. B. (Ed.). Vigor de sementes: conceitos e testes. Londrina: ABRATES. p.2-24, 1999.

RAJALA, A.; PELTONEN-SAINIO, P. Plant growth regulator effects on spring cereal root and shoot growth. Agronomy Journal, v. 5, p. 936-943, 2001.

SALISBURY, F. B.; ROSS, C. W. Plant Physiology. 4ed. Belmont: Wadworth, 1991.

SANTOS, C. M. G.; VIEIRA, E. L. Efeito de bioestimulante na germinação de sementes, vigor de plântulas e crescimento inicial do algodoeiro. Magistra, v. 17, p. 124-130, 2005.

SILVA, J. I. C. et al. Uso de estimulantes de crescimento radicular associado a doses de fósforo na cultura do feijoeiro. Agrarian, v. 2, p. 47-62, 2009.

TAIZ, L.; ZEIGER, E. Fisiologia vegetal. Porto Alegre: Artmed, 2009.

VIEIRA, E. L.; CASTRO, P. R. C. Ação de bioestimulante na germinação de sementes, vigor de plântulas, crescimento radicular e produtividade de soja. Revista Brasileira de Sementes, v. 23, p. 222-228, 2001.

VIEIRA, E. L.; MONTEIRO, C. A. Hormônios vegetais. In: CASTRO, P. R. C.; SENA, J. O. A.; KLUGE, R. A. (Eds.). Introdução à fisiologia do desenvolvimento vegetal. Maringá: EDUEM, 2002. 